\title{
Effect of different acidity modifications on the activity and selectivity on H-ZSM5 zeolites in $\boldsymbol{n}$-butene isomerization
}

\author{
Emre Kiliç • Selahattin Yilmaz
}

Received: 25 August 2013/Accepted: 23 January 2014/Published online: 9 February 2014

(C) Akadémiai Kiadó, Budapest, Hungary 2014

\begin{abstract}
H-ZSM-5 was modified by silylation [tetraethylorthosilicate (TEOS) and triaminopropyltriethoxysilane], alkali $(\mathrm{NaOH})$, acid $(\mathrm{HCl})$ and ammoniumhexafluorosilicate (AHFS) treatments. The parent and modified zeolite forms were tested in $n$-butene isomerization. Modifications affected total acidities, the strength of the acid sites, pore sizes and surface areas of the H-ZSM-5 differently. The modifications decreased the conversion obtained by the parent catalyst. TEOS and alkali modifications did not promote formation of isobutene. Pre-alkali treatment before acid treatment increased selectivity to isobutene from 56.0 to $66.7 \%$, while conversion changed a little, it dropped from 52 to $50 \%$. AHFS modification provided the highest enhancement in selectivity to isobutene $(87.5 \%)$ for which $n$-butene conversion was dropped by about $10 \%$ compared to H-ZSM-5. This was attributed to a slight modification of the pore size and to the reduction in strong and weak acid sites and generation of new Lewis acid sites.
\end{abstract}

Keywords H-ZSM5 - Modification · Acidity · Isomerization · Isobutene

\section{Introduction}

In the last decades, skeletal isomerization of $n$-butene to isobutene has attracted much interest [1-5]. The studied catalysts varied from metal oxides to amorphous or crystalline aluminosilicates. These studies showed that improvements in isobutene selectivity could be achieved by the choice of catalyst type, suitable pore size and shape, or by varying parameters such as crystallite size, morphology, and Si/Al

\footnotetext{
E. Kiliç · S. Yilmaz (ه)

Department of Chemical Engineering, Izmir Institute of Technology, Urla Izmir 35430, Turkey

e-mail: selahattinyilmaz@iyte.edu.tr

E. Kiliç

e-mail: emrekilic@iyte.edu.tr
} 
ratio, or by modifications such as extra framework cation exchange, isomorphous substitution, pore blockage and elimination of acid sites.

Three different mechanisms, monomolecular, bimolecular and pseudo-monomolecular, have been proposed in the literature for skeletal isomerization of $n$-butene [1, 6-10]. Monomolecular mechanism occurs on the Brønsted acid sites of the catalyst. This mechanism requires a highly energetically and thermodynamically unfavorable ring opening to form primary carbenium ion as an intermediate. Monomolecular mechanism could explain the high selectivity to isobutene. The bimolecular mechanism includes dimerization, isomerization and cracking steps. Through this mechanism, the main by-products, propenes and pentenes, are formed. The dimerization of $n$-butene does not directly occur since this would require a primary carbenium ion. In the pseudo-monomolecular mechanism, the active sites would be the coke instead of the Brønsted acid sites and would not, therefore, require a primary carbenium ion. The suppression of cracking by-products can be obtained by adjusting pore size (shape selectivity) of the catalyst such that bimolecular intermediate cannot form due to space constraints, or by adjusting the acidity of the catalysts, such that the rate of formation of $\mathrm{C}^{=}$dimer intermediate is lowered.

The most promising catalysts for the selective isomerization of $n$-butenes are found to be 10 -membered ring (10-MR) molecular sieves, such as ferrierite, SAPO11 and ZSM-22 [6] and ZSM-5 zeolites [11]. Their pore sizes are optimal for $n$ butene diffusion, and they can suppress the bimolecular mechanism. Yang et al. [4] studied 1-butene isomerization over aluminophosphate molecular sieves (SAPO-11, MeAPO-11) and ZSM-22. They found that acidic sites of medium strength were responsible for high selectivity.

Various methods have been applied to modify acidity (strength, acid type and amount) and textural properties of zeolites. Houzvicka et al. [6] tried to change acidity of H-ZSM5 by isomorphous substitution of different metals ( $\mathrm{Ga}, \mathrm{Fe}, \mathrm{B})$ into its lattice. It was found that acidity of the catalysts was not significantly affected; as a result, selectivity to isobutene was not improved. Song et al. [12] modified the acidity of the $\mathrm{H}-\mathrm{ZSM} 5$ catalyst by alkali $(\mathrm{NaOH})$ and acid treatment $(\mathrm{HCl})$. It was shown that mild alkali treatment led to the reduction in strong acid sites and did not distinctly change the pore structure. However, severe alkali treatment resulted in the creation of the stronger acid sites and new mesopores. Weber et al. [13] showed that chemical liquid deposition of tetraethylorthosilicate (TEOS) onto H-ZSM5 reduced acid sites without changing pore structure. On the other hand, pore mouth narrowing and pore blocking occurred after chemical vapor deposition. Canizares et al. [3] treated $\mathrm{H}$-ferrierite with ammoniumhexafluorosilicate $\left[\left(\mathrm{NH}_{4}\right)_{2} \mathrm{SiF}_{6}, \mathrm{AHFS}\right]$. This led to a little framework dealumination although $\mathrm{Si} / \mathrm{Al}$ ratio increased slightly, indicating that the most of the extracted aluminum atoms remained in the pores. High AHFS amounts decreased crystallinity, micropore area and volume. AHFS removed external acid sites. Their catalytic activity was evaluated in the skeletal isomerization of $n$-butene. The modified catalyst improved selectivity to isobutene from 45 to $75 \%$. However, $n$-butene conversion was reduced from 53 to $43 \%$.

In light of the literature, it was decided to modify H-ZSM5 zeolites by silylation (TEOS, 3-APES), acid $(\mathrm{HCl})$, alkali $(\mathrm{NaOH})$ and ammoniumhexafluorosilicate 
(AHFS) treatments to understand and assess the role of different modifications on zeolite activity and selectivity in $n$-butene isomerisation. Evaluation of different modifications on the same zeolite will provide more insight into what controls isobutene selectivity.

\section{Materials and methods}

Preparation of H-ZSM5 catalysts

Na-ZSM-5 was synthesized with $\mathrm{SiO}_{2} / \mathrm{Al}_{2} \mathrm{O}_{3}$ ratio of 77 following a method given in literature [2]. Synthesized Na-ZSM-5 was calcined as follows. It was first heated to $300{ }^{\circ} \mathrm{C}$ and kept there for $30 \mathrm{~min}$. This was followed by heating to $540{ }^{\circ} \mathrm{C}$ at a rate of $3{ }^{\circ} \mathrm{C} / \mathrm{min}$ where it was kept for $8 \mathrm{~h}$. After calcination, Na-ZSM-5 was ionexchanged with $0.1 \mathrm{M} \mathrm{NH}_{4} \mathrm{Cl}$ (Sigma-Aldrich, 99.5\%) solution for $6 \mathrm{~h}$ at room temperature under continuous agitation in a water bath to obtain $\mathrm{NH}_{4}$-ZSM5. The ion exchange was applied twice. The sample obtained was washed thoroughly with deionized water until it was free of chloride ions, which was checked using silver nitrate. After drying at $110{ }^{\circ} \mathrm{C}$ for $24 \mathrm{~h}$, it was calcined slowly by heating $\left(3{ }^{\circ} \mathrm{C} /\right.$ min) to $540{ }^{\circ} \mathrm{C}$ and holding at this temperature for $4 \mathrm{~h}$ to form H-ZSM-5. This material was also referred to as parent zeolite.

Finally, the catalyst powders pelletized under $825 \mathrm{MPa}$ were ground and sieved to obtain particles in the size range of 106 and $250 \mu \mathrm{m}$. This particle size minimizes internal diffusional limitations [14].

\section{Modification of H-ZSM-5}

Modification methods and conditions which will affect H-ZSM-5 properties slightly (acidity, pore size and structure) were selected based on literature studies.

\section{Silylation}

Silylation was performed by chemical liquid deposition method using TEOS and 3-APES [15]. For TEOS deposition, $1.5 \mathrm{~g}$ zeolite was added to $10 \mathrm{ml}$ hexane. Then, $0.03 \mathrm{ml}$ of TEOS/g-catalyst was added into this mixture and stirred for $1 \mathrm{~h}$ at room temperature. The slurry obtained was washed thoroughly with deionized water to remove excess TEOS and centrifuged to obtain modified zeolites. After drying overnight at ambient conditions, they were dried at $110{ }^{\circ} \mathrm{C}$ for $24 \mathrm{~h}$ and calcined at $550{ }^{\circ} \mathrm{C}$ for $6 \mathrm{~h}$.

3-APES-modified zeolite catalyst was prepared by immersing $9.6 \mathrm{~g}$ parent zeolites into a $100 \mathrm{ml}$ ethanol solution containing $1.46 \mathrm{~g}$ of 3-APES. Ethanol was subsequently removed by evaporation at $90{ }^{\circ} \mathrm{C}$ [16]. The remaining sample was washed thoroughly with deionized water, centrifuged and allowed to dry overnight at ambient conditions. The sample was then dried at $110{ }^{\circ} \mathrm{C}$ for $24 \mathrm{~h}$ and calcined at $540{ }^{\circ} \mathrm{C}$ for $8 \mathrm{~h}$ in order to decompose the organosilane precursors and to form silicamodified H-ZSM5. 


\section{Mild alkali treatment}

A method given in the literature was applied for mild alkali treatment of H-ZSM-5 [12]. A zeolite sample of $3.5 \mathrm{~g}$ was added to $200 \mathrm{ml}$ of $0.05 \mathrm{M}$ aqueous $\mathrm{NaOH}$ (Fluka, $98 \%$ ) solution at $70{ }^{\circ} \mathrm{C}$ and stirred for $2 \mathrm{~h}$. The slurry was then cooled down immediately using an ice-water bath, filtered and washed thoroughly till the $\mathrm{pH}$ of the filtration solution decreased to 7 . This was followed by drying at $120{ }^{\circ} \mathrm{C}$ for $10 \mathrm{~h}$ and calcination at $520{ }^{\circ} \mathrm{C}$ for $8 \mathrm{~h}$.

\section{Pre-alkali treatment and acid treatment}

H-ZSM-5 weighing $3.5 \mathrm{~g}$ was first treated with $200 \mathrm{ml}$ of $0.1 \mathrm{M}$ aqueous $\mathrm{NaOH}$ solution at $70^{\circ} \mathrm{C}$ in a shot bottle for $8 \mathrm{~h}$ (severe alkali treatment) [12]. Subsequently, it was washed, dried and calcined as for mild alkali treatment. The severe alkali-treated sample was then subjected to acid treatment by adding $5 \mathrm{~g}$ of alkali-treated sample to $200 \mathrm{ml}$ of $0.1 \mathrm{M} \mathrm{HNO}_{3}$ (Merck, $65 \%$ ) solution heated to $70{ }^{\circ} \mathrm{C}$. The slurry obtained was stirred for $24 \mathrm{~h}$. After cooling down the slurry immediately in an ice bath and filtering, the remaining sample was then successively washed thoroughly with deionized water, centrifuged and allowed to dry at ambient conditions overnight. The modified sample was then dried in oven and calcined as for alkali treatment. For acid modification alone, only the same acid treatment was applied.

\section{AHFS treatment}

First, $1.0 \mathrm{~g} \mathrm{H}-\mathrm{ZSM}-5$ was added into the $100 \mathrm{ml}$ of $0.8 \mathrm{M}$ sodium acetate solution at $\mathrm{pH} 6.7$ [17]. Second, the mixture was heated to $80{ }^{\circ} \mathrm{C}$ under stirring. Third, $20 \mathrm{ml}$ of $1.2 \mathrm{mmol}$ AHFS was added drop wise to the mixture under stirring for $3 \mathrm{~h}$ at $80{ }^{\circ} \mathrm{C}$. Fourth, the modified zeolite was recovered by filtration and washed thoroughly with deionized water to eliminate the unreacted AFHS. The solution was centrifuged and powder washing was repeated till solution $\mathrm{pH}$ became 7 . After that it was allowed to dry at ambient conditions overnight. This was followed by drying at $110{ }^{\circ} \mathrm{C}$ for $24 \mathrm{~h}$ and calcination at $550{ }^{\circ} \mathrm{C}$ for $4 \mathrm{~h}$.

\section{Characterization of catalysts}

The crystalline structures of the catalysts were determined by Philips X'Pert diffractometer with $\mathrm{CuK}_{\alpha}$ radiation. The scattering angle $2 \theta$ was changed from $5^{\circ}$ to $70^{\circ}$, with a step length of $0.02 \%$ s.

The morphologies of the samples were investigated by Philips SFEG 30S scanning electron microscopy (SEM).

The textural properties of the catalysts were determined by Micromeritics ASAP 2010 model static volumetric adsorption instrument. The samples were dried in an oven at $110{ }^{\circ} \mathrm{C}$ overnight prior to degassing. Prior to adsorption experiments, the zeolites were outgassed at $300{ }^{\circ} \mathrm{C}$ for $24 \mathrm{~h}$ under $5 \mu \mathrm{mHg}$ vacuum. 
The acidity of the samples were determined by temperature-programmed desorption of ammonia ( $\mathrm{NH}_{3}$-TPD) using a Micromeritics AutoChem II Chemisorption Analyzer instrument. The sample was heated up to $500{ }^{\circ} \mathrm{C}$ by increasing the temperature at a rate of $5{ }^{\circ} \mathrm{C} / \mathrm{min}$ and keeping at this temperature for $1 \mathrm{~h}$ under He flow of $70 \mathrm{ml} / \mathrm{min}$. Then, the sample was cooled under He flow of $30 \mathrm{ml} / \mathrm{min}$ to $90{ }^{\circ} \mathrm{C}$ at a rate of $5{ }^{\circ} \mathrm{C} / \mathrm{min}$. This was followed by switching the flow to $\mathrm{NH}_{3}-\mathrm{He}$ gas mixture at the rate of $30 \mathrm{ml} / \mathrm{min}$ for $30 \mathrm{~min}$. Physically adsorbed $\mathrm{NH}_{3}$ was removed by degassing the sample at $90{ }^{\circ} \mathrm{C}$ under a He flow of $70 \mathrm{ml} / \mathrm{min}$ for $120 \mathrm{~min}$ and then at a flow rate of $30 \mathrm{ml} / \mathrm{min}$ for $150 \mathrm{~min}$. $\mathrm{NH}_{3}$ desorption from the sample was analyzed by heating the sample at the rate of $10{ }^{\circ} \mathrm{C} / \mathrm{min}$ from 90 to $600{ }^{\circ} \mathrm{C}$. TCD signal was recorded during the $\mathrm{NH}_{3}$-TPD.

The acidity measurements of the catalysts were also carried out by IR spectroscopy with pyridine adsorption/desorption method. IR analysis was carried out between 400 and $4,000 \mathrm{~cm}^{-1}$ with Shimadzu FTIR-8201 model Fourier transform infrared spectrometer using the $\mathrm{KBr}$ pellet technique. $\mathrm{KBr}$ pellets were prepared by pressing a mixture of $4.5 \mathrm{mg}$ catalyst sample and $150 \mathrm{mg} \mathrm{KBr}$. The pellets prepared were dehydrated under vacuum $\left(2 \times 10^{-2} \mathrm{mmHg}\right)$ at $400{ }^{\circ} \mathrm{C}$ for $2 \mathrm{~h}$. The pellets were contacted with pyridine pellets at $150{ }^{\circ} \mathrm{C}$ for $30 \mathrm{~min}$. After removing physically absorbed pyridine by keeping pellet under vacuum $\left(2 \times 10^{-2} \mathrm{mmHg}\right)$ at $150{ }^{\circ} \mathrm{C}$ for $30 \mathrm{~min}$, the samples were analyzed by FTIR.

\section{Catalyst testing}

A fixed bed reactor was used for testing the catalysts in $n$-butene skeletal isomerization. Tests were carried out in a quartz tubular reactor $(10 \mathrm{~mm}$ in diameter and $65 \mathrm{~cm}$ in length) heated by a tubular furnace. The reactor feed consisted of $7.27 \%$ 1-butene in $\mathrm{N}_{2}$. Flow rates of gases were set and controlled by mass flow controllers. The reaction was performed at $375{ }^{\circ} \mathrm{C}$ for a catalyst loading of $50 \mathrm{mg}$ into the reactor (WHSV of $22 \mathrm{~h}^{-1}$ ).

The reactor effluent was connected to the sampling loop system of gas chromatography (Agilent Technologies 6890N Network GC System) for online gas analysis. The online gas chromatograph was equipped with a flame ionization detector (FID) and a fumed silica $\mathrm{KCl}$ column (GS Alumina $\mathrm{KCl}, 50 \mathrm{~m} \times 0.53 \mathrm{~mm}$ ).

\section{Results and discussions}

\section{Characterization results}

SEM analysis showed that synthesized H-ZSM5 had spherical crystallites which were not affected by modifications (results not given). An average crystallite size was calculated as $700 \mathrm{~nm}$ from the sizes of 30 particles taken from the SEM images. XRD results showed that ZSM5 structure was preserved after the modifications (results not shown).

Textural and physicochemical properties of the parent catalyst and its modified forms are shown in Table 1 . TEOS deposition reduced the surface area, pore size 
Table 1 Textural and physicochemical properties of H-ZSM5 and its modified forms

\begin{tabular}{lllllll}
\hline Catalysts & $\begin{array}{l}\text { BET surface } \\
\text { area }\left(\mathrm{m}^{2} / \mathrm{g}\right)\end{array}$ & $\begin{array}{l}\text { Micropore } \\
\text { area }\left(\mathrm{m}^{2} / \mathrm{g}\right)\end{array}$ & $\begin{array}{l}\text { Micropore } \\
\text { volume } \\
\left(\mathrm{cm}^{3} / \mathrm{g}\right)\end{array}$ & $\begin{array}{l}\mathrm{H} . \mathrm{K} . \text { pore } \\
\text { diameter }(\mathrm{A})\end{array}$ & $\begin{array}{l}\mathrm{SiO}_{2} \\
/ \mathrm{Al}_{2} \mathrm{O}_{3}\end{array}$ & $\begin{array}{l}\mathrm{Al} \text { content } \\
(\mathrm{mmol} / \mathrm{g})\end{array}$ \\
\hline H-ZSM5 & 401.2 & 348.2 & 0.159 & 5.9 & 76.3 & 0.29 \\
H-ZSM5-TEOS & 362.4 & 289.6 & 0.145 & 5.3 & 79.4 & 0.25 \\
H-ZSM5-3APES & 276.5 & 213.9 & 0.122 & 3.5 & 170.2 & 0.18 \\
H-ZSM5-AHFS & 394.3 & 323.5 & 0.150 & 5.8 & 85.1 & 0.26 \\
H-ZSM5-NaOH & 438.1 & 336.8 & 0.171 & 5.5 & 77.1 & 0.23 \\
H-ZSM5-NaOH-HCl & 375.4 & 292.3 & 0.196 & 5.5 & 78.1 & 0.25 \\
H-ZSM5-HCl & 355.9 & 296.5 & 0.138 & 4.9 & 154.2 & 0.15 \\
\hline
\end{tabular}

and micropore volume. $\mathrm{SiO}_{2} / \mathrm{Al}_{2} \mathrm{O}_{3}$ ratio increased slightly. The external surface area increased. These results indicated that silylation took place on the surface and caused pore narrowing and blockage. Hibino et al. [20] and Weber et al. [13] reported pore narrowing and increase in the external surface area of ZSM-5 upon silicon alkoxides deposition [13, 15, 18-20].

The most significant decrease in BET surface, micropore volume and pore size was observed by 3-APES treatment. A large increase in $\mathrm{SiO}_{2} / \mathrm{Al}_{2} \mathrm{O}_{3}$ ratio was obtained (Table 1). A significant silica deposition was achieved, and it narrowed and blocked zeolite channels. Since 3-APES is a large molecule, most of silica probably deposited on the external surface as reported by Ding et al. [21].

The textural properties of the H-ZSM-5 were affected the least by AHFS treatment compared to other modifications. The surface area loss was not significant and the pore size dropped a bit (Table 1). $\mathrm{SiO}_{2} / \mathrm{Al}_{2} \mathrm{O}_{3}$ ratio increased slightly, which indicated dealumination. This was in agreement with study by Canizares et al. [17]. They reported that AHFS caused dealumination and extracted $\mathrm{Al}$ atoms remained in the pore. Kumar et al. [22] also found mild dealumination by AHFS treatment. Accordingly, Triantafillidis et al. [23] reported that AHFS treatment was appropriate for preparation of moderately dealuminated H-ZSM5 samples, which were free from extra framework $\mathrm{Al}$.

As opposed to other treatment methods, the mild alkali treatment increased the BET surface area and micropore volume. Slight dealumination was also observed as Al content decreased. Dealumination is reported to accompany desilication [24] which might explain the slight increase in $\mathrm{SiO}_{2} / \mathrm{Al}_{2} \mathrm{O}_{3}$ ratio observed. The drop in the pore size was probably due to precipitation of silica and alumina species dissolved from zeolite onto the surface of ZSM-5 crystals. Severe alkali pretreatment and acid treatment decreased surface area and increased micropore volume. It dropped aluminum content which raised $\mathrm{SiO}_{2} / \mathrm{Al}_{2} \mathrm{O}_{3}$ ratio. These could be related to a slight desilication and dealumination taking place as discussed by Song et al. [12]. This led to a drop in the pore size. The acid treatment alone decreased BET surface area, micropore volume and pore size. Al content was dropped significantly due to dealumination which doubled $\mathrm{SiO}_{2} / \mathrm{Al}_{2} \mathrm{O}_{3}$. 

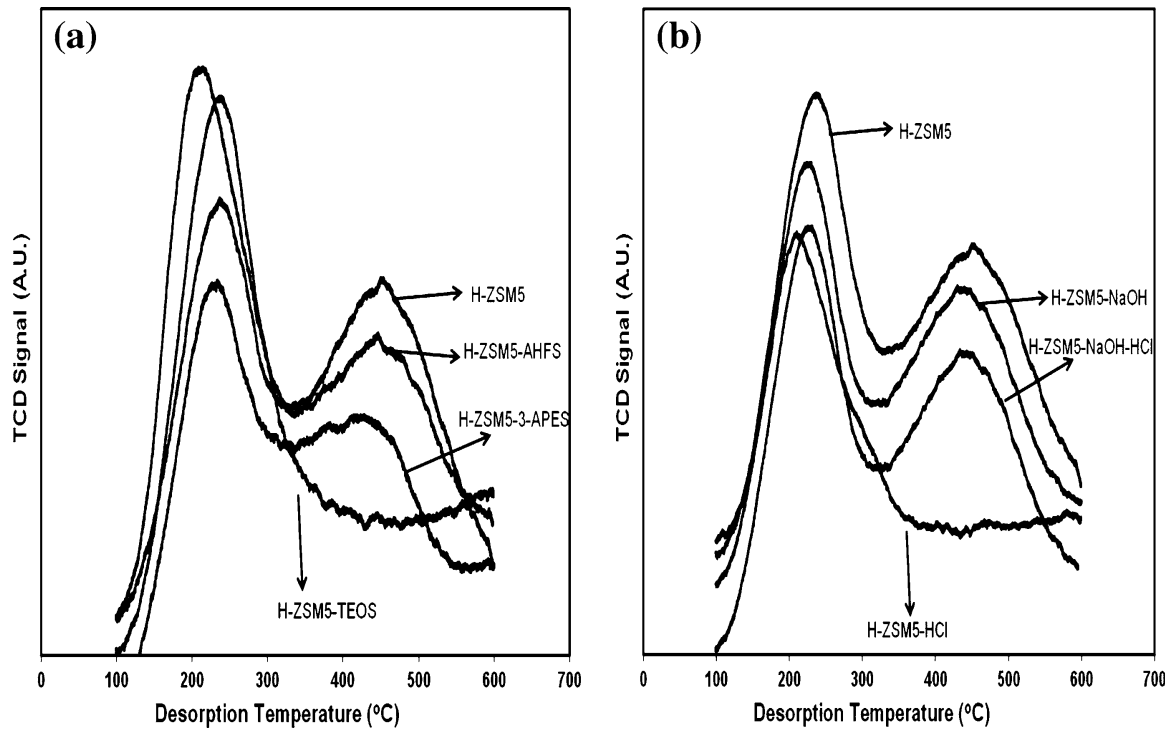

Fig. $1 \mathrm{NH}_{3}$-TPD profiles of different catalysts, a H-ZSM5, H-ZSM5-TEOS, H-ZSM5-APES, H-ZSM5AHFS, b H-ZSM5, H-ZSM5-NaOH, H-ZSM5-NaOH-HCl, H-ZSM5-HCl

Temperature-programmed desorption of ammonia allows quantitative determination of the total amount of the acid sites. The $\mathrm{NH}_{3}$-TPD profiles of the parent H-ZSM5 and their modified samples are presented in Fig. 1. It can be seen that most samples exhibited the typical double-peak characteristic of zeolites with MFI structure [25]. The desorption peaks centered at a low temperature $\left(240{ }^{\circ} \mathrm{C}\right)$ and a high temperature $\left(450^{\circ} \mathrm{C}\right)$ are referred as weak and strong acid sites, respectively [26]. The total acidity of each catalyst was calculated and tabulated in Table 2. There were no large differences between the total acidity of parent and modified catalysts. This indicated that besides the total influence of acidity, the strength and type of acid must be taken into account to explain results obtained in the skeletal isomerization of $n$-butene to isobutene. However, the quantity of weak and strong acid sites changed differently with different modifications pursued.

The acidity types of H-ZSM5 and their modified forms were determined by pyridine adsorption. It was observed from each spectrum that all the catalysts had Brønsted and Lewis acid sites (results not given). Brønsted and Lewis sites amounts were determined from the areas under the IR peaks centered at wavenumbers of 1,450 and $1,545 \mathrm{~cm}^{-1}$, respectively (Table 2). Since pyridine adsorption on H-ZSM5 (at low temperatures and short adsorption times, as in our case) is reported to occur only in the outer part of the crystallites [17], these values can be interpreted as a measure of surface acidity.

TEOS modification decreased total concentration of acid sites of H-ZSM5; strong acid sites were decreased by half while weak acid sites increased slightly. TEOS molecules react with two adjacent hydroxyl groups on the zeolite surface during TEOS deposition [27]. TEOS decomposes to the $\mathrm{Si}\left(\mathrm{C}_{2} \mathrm{H}_{5}\right)_{3}$ and $\mathrm{C}_{2} \mathrm{H}_{5} \mathrm{OH}$. Ethanol diffuses into the solution from the surface, whereas $\mathrm{Si}\left(\mathrm{C}_{2} \mathrm{H}_{5}\right)_{3}$ molecules remain on 
Table 2 Acidity of H-ZSM5 and its modified samples

\begin{tabular}{llllll}
\hline Catalysts & $\begin{array}{l}\text { Total Acidity } \\
\left(\mathrm{mmolNH}_{3} / \mathrm{g}_{\mathrm{ca}} \mathrm{t}\right)\end{array}$ & $\begin{array}{l}\text { Weak Acid Sites } \\
\left(\mathrm{mmolNH}_{3} / \mathrm{g}_{\mathrm{cat}}\right)\end{array}$ & $\begin{array}{l}\text { Strong Acid Sites } \\
\left(\mathrm{mmolNH}_{3} / \mathrm{g}_{\mathrm{cat}}\right)\end{array}$ & $\begin{array}{l}\text { Brønsted Area } \\
\left(1,540 \mathrm{~cm}^{-1}\right)\end{array}$ & $\begin{array}{l}\text { Lewis Area } \\
\left(1,450 \mathrm{~cm}^{-1}\right)\end{array}$ \\
\hline H-ZSM5 & 0.394 & 0.189 & 0.205 & 2.51 & 0.89 \\
H-ZSM5-TEOS & 0.319 & 0.213 & 0.106 & - & - \\
H-ZSM5-3APES & 0.262 & 0.129 & 0.133 & 1.79 & 0.34 \\
H-ZSM5-AHFS & 0.353 & 0.167 & 0.187 & 1.60 & 0.98 \\
H-ZSM5-NaOH & 0.368 & 0.173 & 0.195 & 1.36 & 0.71 \\
H-ZSM5- & 0.338 & 0.175 & 0.163 & 0.91 & 0.61 \\
$\quad$ NaOH-HCl & & & & & \\
H-ZSM5-HCl & 0.319 & 0.196 & 0.123 & 1.92 & 0.67 \\
\hline
\end{tabular}

the acid sites. After the calcination, the acid sites on the surface were coated by $\mathrm{SiO}_{2}$.

3-APES modification reduced the number of strong and weak acid sites substantially. This could be due to pore blockage and high amount of silica deposition observed. The amounts of both Brønsted and Lewis acid sites were also decreased significantly. 3-APES adsorb strongly on acid sites [16]. After the combustion of the organic component in the anchored organosilane molecules, $\mathrm{SiO}_{\mathrm{x}}$ species selectively replace external hydroxyls with $\mathrm{SiO}_{\mathrm{x}}$ species lacking acidic hydroxyls.

AHFS also decreased the amount of strong and weak acid sites. Brønsted sites were decreased to some extent. The reduction in acidity could be due to substitution of $\mathrm{Al}$ in the framework by $\mathrm{Si}$ atoms (Table 1). Al atoms extracted from the framework might remain in the pores and might form new Lewis acid centers $([3,22])$. This might be the reason for the slight increase observed in the amount of Lewis acid sites. Similarly, Canizares et al. [17] found that AHFS treatment removed mainly external Brønsted and Lewis acid sites of ferrierite with a marked improvement in the number of medium strength acid sites.

After alkali treatment, some reduction in strong and weak acid sites was observed. The change in acidity could be due to dealumination and desilication observed (Table 1). Both Brønsted and Lewis acid sites were reduced. That is, external surface acidity was lowered. The pre-alkali (severe) and acid treatment decreased strong acid sites significantly while it dropped weak acids slightly. The change in acidity was due to desilication and dealumination. Song et al. [12] reported that severe alkali treatment (high $\mathrm{NaOH}$ concentration) caused extra framework alumina formation which was removed after $\mathrm{HCl}$ treatment. External acidity was decreased significantly.

Acid treatment alone decreased strong acid sites significantly while weak acid sites did not change much. The substantial removal of $\mathrm{Al}$ from the structure led to decrease in acidity. Dealumination of $\mathrm{H}-\mathrm{ZSM} 5$ by $\mathrm{HCl}$ was also reported by Kooyman et al. [28]. The drop observed in Brønsted and Lewis acid sites showed removal of external acid sites upon acid treatment. 


\section{Reaction tests}

Conversion of 1-butene and selectivity to isobutene were calculated from the following equations,

$$
\begin{aligned}
& \text { Conversion }(\text { mole } \%)=\frac{\left(1-\text { butene }_{\text {in }}\right)-\left(n-\text { butene }_{\text {out }}\right)}{\left(1-\text { butene }_{\text {in }}\right)} \\
& \text { Selectivity }(\text { mole } \%)=\frac{\text { Isobutene }_{\text {out }}}{\left(1-\text { butene }_{\text {in }}\right)-\left(n-\text { butene }_{\text {out }}\right)}
\end{aligned}
$$

Initial product distributions obtained over H-ZSM5 and its modified forms except $\mathrm{H}-\mathrm{ZSM} 5-\mathrm{HCl}$ (which gave low conversion and selectivity) are given in Table 3. Different product distributions were obtained with the catalysts prepared. These products include various hydrocarbons such as $\mathrm{C} 1, \mathrm{C} 2, \mathrm{C} 3$ and $\mathrm{C} 5+$ as well as isobutene. Large amounts of secondary products, propene, propane and pentenes, formed indicated that bimolecular mechanism was significant over H-ZSM5 catalysts at short time on stream. C1, C2, C3 and C5 hydrocarbons are formed through dimerization or oligomerization followed by cracking. And isobutene is formed through skeletal isomerization. A geometric isomerization between cis-2butene and trans-2-butene and a double-bond migration can proceed on solid acid catalysts simultaneously. Therefore, the product distribution is very complicated because the extent of reaction varies according to reaction conditions and catalysts. Byggningsbacka et al. [7] proposed a detailed mechanism for product distribution for skeletal isomerization of $n$-butene.

Table 3 Product distributions, conversions and selectivity to isobutene obtained over H-ZSM5 and its modified forms for the reaction time of $10 \mathrm{~min}$ at $\mathrm{T}=375{ }^{\circ} \mathrm{C}$ and WHSV $=22 \mathrm{~h}^{-1}$

\begin{tabular}{lcclcc}
\hline Comp. (mol\%) & Sample & & & \\
\cline { 2 - 6 } & H-ZSM5 & $\begin{array}{l}\text { H-ZSM5- } \\
\text { TEOS }\end{array}$ & $\begin{array}{l}\text { H-ZSM5- } \\
\text { NaOH-HCl }\end{array}$ & $\begin{array}{l}\text { H-ZSM5- } \\
\text { AHFS }\end{array}$ & $\begin{array}{l}\text { H-ZSM5- } \\
\text { NaOH }\end{array}$ \\
\hline Methane & 0.01 & 0.03 & 0.06 & 0.01 & 2.17 \\
Ethane & 2.71 & 3.34 & 2.14 & 0.59 & 1.12 \\
Ethylene & 8.15 & 2.85 & 1.14 & 1.03 & 1.50 \\
Propane & 2.59 & 1.18 & 3.01 & 1.29 & 2.11 \\
Propylene & 5.94 & 2.96 & 4.43 & 1.74 & 5.24 \\
Isobutane & 0.72 & 2.32 & 3.57 & 0.49 & 3.48 \\
$n$-Butane & 0.56 & 1.98 & 2.41 & 0.51 & 3.64 \\
Trans-2-butene & 18.81 & 16.61 & 14.88 & 19.93 & 10.63 \\
1-Butene & 10.73 & 19.82 & 15.51 & 19.96 & 19.57 \\
Isobutene & 29.41 & 31.38 & 33.40 & 37.88 & 29.93 \\
Cis-2-butene & 17.86 & 15.08 & 18.02 & 15.52 & 17.84 \\
1-Pentene & 2.14 & 1.77 & 1.64 & 0.67 & 1.41 \\
(C2 + C3) ${ }^{-}$/C5 & 6.58 & 3.28 & 3.40 & 4.13 & 4.78 \\
Selectivity & 55.91 & 64.71 & 64.74 & 84.95 & 57.60 \\
Conversion & 52.60 & 48.49 & 51.59 & 44.59 & 51.96 \\
\hline
\end{tabular}


(a)

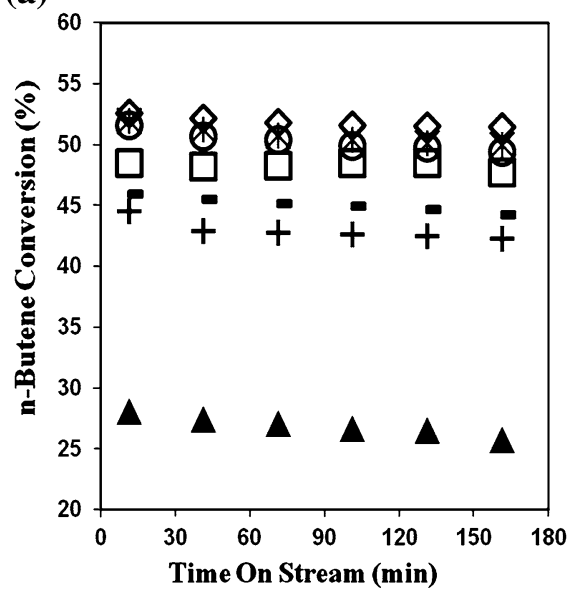

(b)

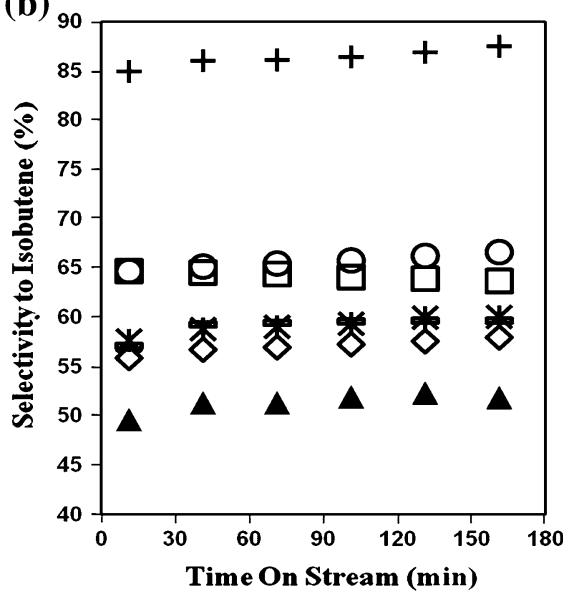

Fig. 2 Comparison of $n$-butene conversions (a), selectivities to isobutene over different catalysts (b). Reaction conditions, $\mathrm{T}=375{ }^{\circ} \mathrm{C}$ and WHSV $=22 \mathrm{~h}^{-1}$. Catalysts: $\bullet$ H-ZSM5; - -H-ZSM5-3APES; $\theta$ H-ZSM5-NaOH-HCl; $\rightarrow$ H-ZSM5-HCl; +H-ZSM5-AHFS; * H-ZSM5-NaOH; ॄH-ZSM5-TEOS

Modifications decreased selectivity toward the by-products, pentene, ethylene and propylene, strongly but not all with the same trend. Houzvicka et al. [6] and Lee et al. [26] stated that strong acid sites present on zeolites were responsible for the formation of by-products mainly propane and propylene, through the bimolecular mechanism. As discussed in the introduction, bimolecular reactions involve cracking reactions. Propylene and ethylene are predominant over strong acid sites. The decrease in (ethylene + propylene)/pentenes ratio with the modifications indicated drop in the extent of bimolecular mechanism [17]. Reduction in the acid site density would decrease contact time, as a result less consecutive reactions could occur which might also contribute to increase in selectivity.

The conversions and selectivities obtained over the catalysts are given in Fig. 2a, b. $n$-Butene conversion decreased and selectivity to isobutene increased with reaction time on stream. This was attributed to coke formation. It reduced the catalyst activity and increased selectivity by blockage of unselective active sites and reduction in the space in the pores due to coke deposition, as discussed in literature [1, 7, 8]. H-ZSM5 provided $51.5 \%$ conversion of $n$-butene with $58.0 \%$ selectivity to isobutene. The modifications decreased conversion of $n$-butene obtained over the parent catalyst. The highest drop, about $33 \%$, was obtained after 3-APES deposition. Although this modification caused pore blockage, decreased acidity and surface area significantly, selectivity to isobutene was affected slightly.

The TEOS modification decreased conversion obtained with parent zeolite by $8 \%$. This was attributed to a decrease in strong acid sites. However, it improved the selectivity to isobutene from 58.0 to $63.7 \%$. This was probably due to elimination of easily accessible, non-shape selective acid sites found on the external surface. 
The AHFS treatment lowered the conversions obtained over parent catalyst by about $10 \%$; i.e., to $42.3 \%$. On the contrary, the selectivity to isobutene was enhanced dramatically, from 58.0 to $87.5 \%$. Reduction in conversion was attributed to drop of weak and strong acid sites and to noteworthy drop of Brønsted acid sites and slight increase Lewis acid sites. This acidity change together with slight decrease in pore size enhanced the selectivity.

Mild alkali treatment did not change activity and selectivity of the parent catalyst significantly; the conversion decreased by about $3 \%$ while selectivity to isobutene increased slightly, to $60.1 \%$. This might be due to the reduction observed in strong and weak acid sites. Pre-alkali and acid treatment affected activity as for alkali alone. However, it improved parent catalyst selectivity by $10 \%$. This was probably due to significant drop in strong acid sites and the decrease in the external acidity. Acid treatment alone reduced parent's catalysts conversion by $10 \%$. However, selectivity to isobutene was not affected. The drop in activity was related to the removal of strong acid sites.

\section{Conclusions}

The crystal structure of the H-ZSM-5 was preserved after modifications. The modifications affected the acidity and textural properties of the H-ZSM5 differently. The distribution of acid site strength and pore size had considerable effects on isobutene selectivity. The TEOS modification narrowed and blocked pores and decreased strong acid sites substantially. However, no significant change in conversion and selectivity was obtained. 3-APES narrowed and closed the pore openings and reduced acidity. It deteriorated the parent catalysts selectivity. AHFS treatment provided the best improvement in selectivity. By this modification, strong and weak acid sites were decreased and Lewis acidity was increased while pore size changed slightly. The alkali treatment caused dealumination and desilication. Although the total acidity decreased to some extent and external acidity decreased considerably, selectivity to isobutene was almost the same as that of the parent catalyst. Pre-alkali and acid treatment decreased strong acids and external acidity strongly. Nevertheless, conversions similar to the parent catalyst were obtained as the selectivity increased by about $10 \%$. Acid treatment affected acidity significantly. It gave lower conversions and selectivities than the parent catalyst.

Acknowledgments The financial support from Turkish State Planning Organization (2002K120390) and Izmir Institute of Technology Research Funds (2008IYTE07) are gratefully acknowledged.

\section{References}

1. Houžvička J, Ponec V (1998) The role of the acid strength of the catalysts in the skeletal isomerisation of n-butene. Appl Catal A Gen 174:207-212

2. Nicolaides CP (1999) A novel family of solid acid catalysts: substantially amorphous or partially crystalline zeolitic materials. Appl Catal A Gen 185:211-217

3. Canizares P, Lucas A, Dorado F, Pérez D (2000) Effect of zeolite pore geometry on isomerization of n-butane. Appl Catal A Gen 190:233-239 
4. Yang SM, Lin JY, Guo DH, Liaw SG (1999) 1-Butene isomerization over aluminophosphate molecular sieves and zeolites. Appl Catal A Gen 181:113-122

5. Domokos L, Lefferts L, Seshan K, Lercher JA (2000) The importance of acid site locations for n-butene skeletal isomerization on ferrierite. J Mol Catal A Chem 162:147-157

6. Houzvicka J, Hansildaar S, Ponec V (1997) The shape selectivity in the skeletal isomerisation of n-butene to isobutene. J Catal 167:273-278

7. Byggningsbacka R, Lindfors LE, Kumar N (1998) Comparative study of the catalytic properties of ZSM-22 and ZSM-35/ferrierite zeolites in the skeletal isomerization of 1-butene. J Catal 178:611-620

8. Guisnet M, Andy P, Gnep NS, Travers C, Benazzi E (1999) Mechanisms of the skeletal isomerization of n-butene over a HFER zeolite. Influence of coke deposits. Stud Surf Sci Catal 105:1365-1372

9. de Menorval B, Ayrault P, Gnep NS, Guisnet M (2005) Mechanism of $n$-butene skeletal isomerization over HFER zeolites: a new proposal. J Catal 230:38-51

10. Rutenbeck D, Papa H, Freude D, Schwieger W (2001) Investigations on the reaction mechanism of the skeletal isomerization of $n$-butenes to isobutene: part I. Reaction mechanism on H-ZSM-5 zeolites. Appl Catal A Gen 206:57-66

11. Klepel O, Loubentsov A, Böhlmannb W, Papp H (2003) Oligomerization as an important step and side reaction for skeletal isomerization of linear butenes on H-ZSM-5. Appl Catal A Gen 255:349-354

12. Song YQ, Feng YL, Liu F, Kang CL, Zhou XL, Xu LY, Yu GX (2009) Effect of variations in pore structure and acidity of alkali treated ZSM-5 on the isomerization performance. J Mol Catal A Chem 310:130-137

13. Weber RW, Möller KP, Unger M, O'Connor CT (1998) The chemical vapour and liquid deposition of tatraethoxysilane on the external surface of ZSM-5. Micropor Mater 23:179-187

14. Byggningsbacka R, Lindfors LE, Kumar N (1998) Catalytic activity of ZSM-22 zeolites in the skeletal isomerization of 1-butene. Ind Eng Chem Res 36:2990-2995

15. Yue YH, Tang Y, Liu Y, Gao Z (1996) Chemical liquid deposition zeolites with controlled poreopening size and shape-selective separation of isomers. Ind Eng Chem Res 35:430-433

16. Ding W, Meitzner GD, Iglesia E (2002) The effects of silanation of external acid sites on the structure and catalytic behavior of Mo/H-ZSM5. J Catal 206:14-22

17. Canizares P, Carrero A (2003) Dealumination of ferrierite by ammonium hexafluorosilicate treatment: characterization and testing in the skeletal isomerization of $n$-butene. Appl Catal A Gen 24:227-237

18. Limin H, Quanzhi L, Zhiyuan X, Ding G, Guoxing N, Zaiting L, Zhicheng S (1997) Effect of predealumination by $\left(\mathrm{NH}_{4}\right)_{2} \mathrm{SiF}_{6}$ on the properties of ZSM-5 with steam aging treatment. Surf Sci Catal 105:2003-2010

19. Chudasama CD, Sebastian J, Jasra RV (2005) Pore-size engineering of zeolite A for the size/shape selective molecular separation. Ind Eng Chem Res 44:1780-1786

20. Hibino T, Niwa M, Murakami Y (1991) Shape-selectivity over HZSM-5 modified by chemical vapor deposition of silicon alkoxide. J Catal 128:551-558

21. Ding W, Meitzner GD, Iglesia E (2002) The effects of silanation of external acid sites on the structure and catalytic behavior of Mo/H-ZSM5. J Catal 206:14-22

22. Kumar S, Sinha AK, Hegde SG, Sivasanker S (2000) Influence of mild dealumination on physicochemical, acidic and catalytic properties of H-ZSM-5. J Mol Catal A Chem 154:115-120

23. Triantafillidis CS, Vlessidis AG, Nalbandian L, Evmiridis NP (2001) Effect of the degree and type of the dealumination method on the structural, compositional and acidic characteristics of H-ZSM-5 zeolites. Micropor Mater 47:369-388

24. Ogura M, Shinomiya S, Tateno J, Nara Y, Nomura M, Kikuchi E, Matsukata M (2001) Alkalitreatment technique-new method for modification of structural and acid-catalytic properties of ZSM-5 zeolites. Appl Catal A Gen 219:33-43

25. Shang Y, Yang P, Jia M, Zhang W, Wu T (2008) Modification of MCM-22 zeolites with silylation agents: acid properties and catalytic performance for the skeletal isomerization. Catal Commun 9:907-912

26. Lee HC, Woo HC, Ryoo R, Lee KH, Lee JS (2000) Skeletal isomerization of $n$-butenes to isobutene over acid-treated natural clinoptilolite zeolites. Appl Catal A Gen 196:135-142

27. Dai Y, Yang P, Chen L, Liao K (2002) A study on acidity and catalytic property of [B] ZSM-5 catalyst modified with silicon compound by chemical surface deposition of liquid-phase technique. Pet Sci Technol 20:621-632

28. Kooyman PJ, Van der Waal P, Van Bekkum H (1997) Acid dealumination of ZSM-5. Zeolites 18:50-53 